\title{
44531 - TRANEXAMIC ACID REDUCES BLOOD LOSS AFTER OFF-PUMP CORONARY ARTERY BYPASS GRAFTING: A DOUBLE BLIND PLACEBO CONTROLLED STUDY
}

\author{
Tulika Shinghal, Montreal General Hospital, Montreal, QC, Canada; \\ David Bracco, Montreal General Hospital; \\ Nicolas Noiseux, Hotel Dieu de Montreal; \\ Ignacio Prieto, Hotel Dieu de Montreal; \\ Fadi Basile, Hotel Dieu de Montreal; \\ T M Hemmerling, Montreal General Hospital;
}

\section{INTRODUCTION:}

The use of anti-fibrinolytics have been recently challenged in cardiac surgery (1). Aprotinin is effective in reducing blood loss but may carry some risks of anaphylactic reaction and postoperative complications. Tranexamic acid and amino caproic acid have weaker antifibrinolytic activities but seem not related to an increased risk of complications after cardiac surgery. However, one study has shown that in low risk for bleeding cardiac surgery, the use of tranexamic acid is no better than placebo in reducing significant blood loss (2). Off-pump aortocoronary bypass grafting (OPCAB) poses significantly less risk for bleeding in cardiac surgery in comparison to on-pump CABG. We therefore designed a pilot study investigating whether tranexamic acid significantly reduces blood loss after, performed in this hospital setting for $90 \%$ of all aortocoronary bypass grafting.

\section{METHODS:}

Local IRB approval was obtained for this study. 14 patients scheduled for OPCAB were prospectively enrolled in this prospective randomized double blind placebo controlled study. 8 received $100 \mathrm{mg} / \mathrm{kg}$ tranexamic acid over 20 minutes after induction and 6 other received placebo. A strict transfusion policy with a threshold of $70 \mathrm{~g} / \mathrm{L}$ in patients younger than 80 years and $80 \mathrm{~g} / \mathrm{L}$ in older patients was applied. Blood losses and blood component use were recorded from anesthesia induction up to $24 \mathrm{~h}$ after the surgery.

\section{RESULTS:}

Patient were comparable in pre-operative risk factors, received a mean of 3.5 bypasses with a cumulative ischemia time of 18 minutes, a surgery time of 135 minutes. Peroperative blood losses were comparable but patients receiving tranexamic acid had significantly less postoperative bleeding at $4 \mathrm{~h}(\mathrm{p}<0.05), 24 \mathrm{~h}(\mathrm{p}<0.05)$. 


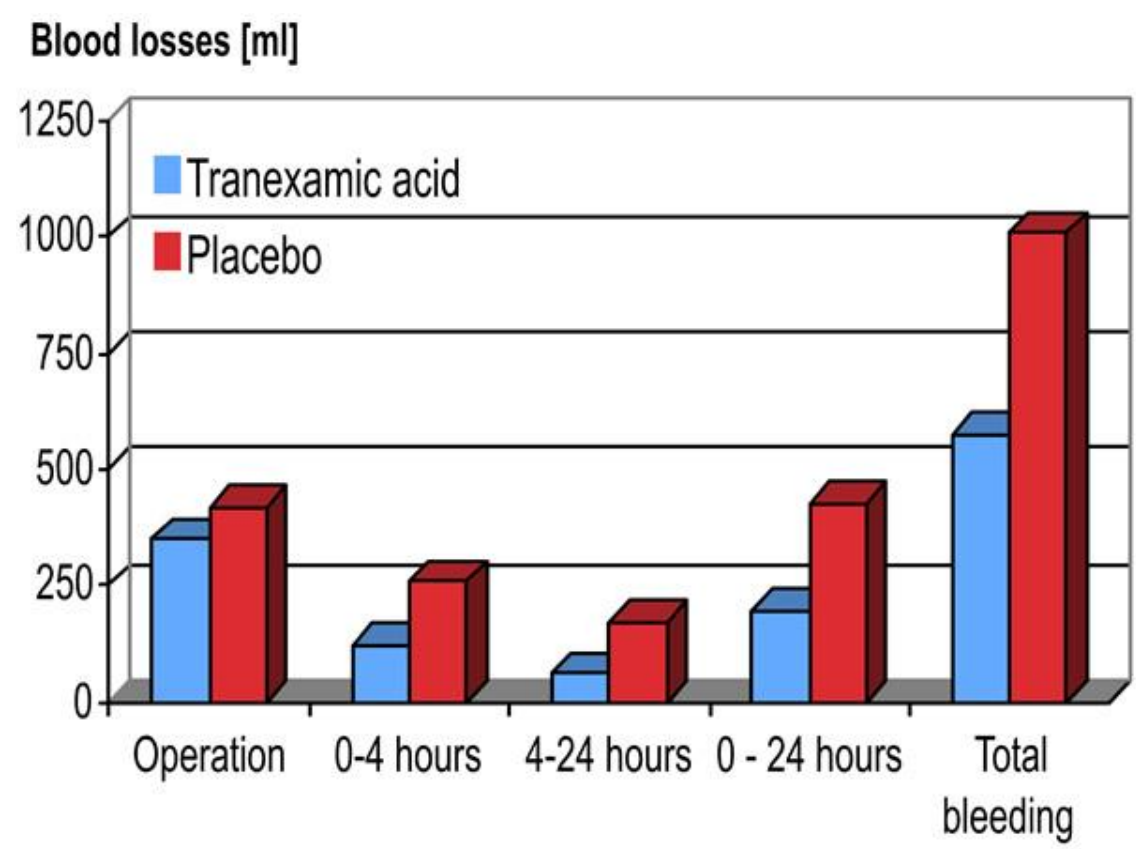

Mean total blood loss amounted $572 \mathrm{ml}$ in the tranexamic acid group versus $966 \mathrm{ml}$ in control patients. The power of the present study was above $80 \%$. No patient received blood products and no postoperative complication was noted.

\section{DISCUSSION:}

The present cohort lack power to detect rare post-operative complications and larger scale studies in OP-CABG are suggested. Tranexamic acid $(100 \mathrm{mg} / \mathrm{kg}$ at induction) significantly decreases blood loss after OPCAB

1 Anesth Analg. 2006; 103: 1067-70

2 Eur J Cardiothorac Surg. 2004; 26: 311-7. 